\title{
Effects of Firing Time and Temperature on Physical Properties of Fired Clay Bricks
}

\author{
Eshetu Tsega ${ }^{1}$, Alemu Mosisa ${ }^{2, *}$, Fekadu Fufa ${ }^{2}$ \\ ${ }^{1}$ Construction Technology and Management Department, College of Engineering, Ambo University, Oromia, Ethiopia \\ ${ }^{2}$ Civil and Environmental Engineering School, Jimma Institute of Technology, Jimma University, Oromia, Ethiopia
}

\section{Email address:}

amosisa@gmail.com (A. Mosisa), mosisalex@yahoo.com (A. Mosisa)

${ }^{*}$ Corresponding author

\section{To cite this article:}

Eshetu Tsega, Alemu Mosisa, Fekadu Fufa. Effects of Firing Time and Temperature on Physical Properties of Fired Clay Bricks. American Journal of Civil Engineering. Vol. 5, No. 1, 2017, pp. 21-26. doi: 10.11648/j.ajce.20170501.14

Received: August 18, 2016; Accepted: August 23, 2016; Published: January 5, 2017

\begin{abstract}
Brick is one of the most widely used conventional construction materials throughout the world. The production cost of clay brick is significantly affected by the cost of energy required for firing. The aim of this research is to investigate the effects of different firing temperatures on the compressive strength (CS), water absorption (WA) and saturation coefficients (SC) of fired clay bricks produced around Jimma Town and evaluate the effect of firing processes in brick manufacturing on the properties, color and appearance of the clay brick. During the production process, the effects of different heating rates on physical and mechanical properties of firing standard bricks were analyzed. In this study, different heating rates were used: slow heating rate and fast heating rate. Changes in the physical and mechanical properties of the fired clay brick were assessed with the increase in the firing temperature firing time. The results show that the CS increased with the increase in the firing temperature. On the contrary, WA and SC of the fired clay bricks decreased with the increase in the firing temperature. Increment in the duration of firing slightly increases the CS and lowers both the WA and WA of the clay brick. In the study area, traditional brick producers did not have firing temperature control device or mechanism in the fired clay brick production. The kiln operator decided the firing temperature and duration. The absence of the device frequently results in the over or under firing of bricks greatly affecting the engineering properties of this widely used contraction material. Therefore, the traditional clay brick producers should install the temperature control device on their kiln or at least needs to be trained how to approximately determine the optimum temperature.
\end{abstract}

Keywords: Burnt Clay Brick, CS, Firing Temperature, Saturation Coefficient, Water Absorption

\section{Introduction}

Bricks are more commonly used in the construction of buildings than any other material, with the exception of wood. Brick and terracotta architecture is dominant within its field and various industries have been developed and invested in the manufacturing of different types of bricks of all shapes and colors. With the advancement of modern machinery, earth moving equipment, powerful electric motors and modern tunnel kilns, making bricks has become far more productive and efficient than ever before $[1,4,5]$. Bricks can be made from a variety of materials the most common being clay, but also calcium silicate and concrete are raw materials for brick production. With clay bricks being the most popular, they are now manufactured using three processes: soft mud, dry press and extruded processing $[1,4,5,7]$.

In the modern brick production fuel oil is used and covers less than $2 \%$ of the total annual brick production $[2,12]$. The annual clay bricks production in Ethiopia is not more than 30 million pieces. This quantity is very small when compared to the amount produced in other countries. Clay bricks are transported hundreds of kilometers from the factories to regional cities in Ethiopia. Traditional clay bricks are widely produced in Jimma and Hollata, Oromia Regional National State, Ethiopia. According to [4, 11, 14, 15], construction materials for wall and distribution of households by construction material have not been well studied and complied in a data base in the country. However, the report shows that about $76.0 \%$ of the country's total households reside in dwelling units with walls constructed 
from wood and mud. These types of houses are more common among urban households $(82.4 \%)$ than rural (74.8\%). Slightly more than $9 \%$ of rural and $1 \%$ of urban households dwell in wood and thatch houses. Households living in housing units with walls constructed of stone and mud constitute $9.1 \%$ in rural and $6.3 \%$ in urban areas. Dwelling units with wall constructed by other types of materials are uncommon $(<10 \%)$ in both the urban and the rural areas. According to this analytical report, in Ethiopia, only $0.1 \%$ used bricks as a walling material. This indicates that the use of clay bricks in the Ethiopian construction industry as a walling material is low. Some of the main reasons are their higher costs when compared with hollow concrete blocks, limited amount and shapes of production. Therefore, scientific in puts supported by researches for the development of the clay brick industry is vital [11-12].

Most of the traditional clay brick production system in and around Jimma is obsolete and produce limited type and amount of clay bricks when compared with other countries [1]. Furthermore, over and under fire clay bricks production is the regular practice of these traditional factories. One of the major contributing factors for this problem is poor kiln firing temperature controlling mechanism. So, besides assessing the kiln firing temperature controlling mechanism of traditional clay bricks production systems, determination of the effect of firing temperature on the compressive strength (CS), water absorption (WA) and saturation coefficient (SC) of clay bricks could be vital input in improving the quality of traditionally produced clay bricks throughout the country.

\section{Sample Collection and Data Analysis}

\subsection{Location of Clay Soil Sampling Sites}

Samples of clay soil were collected from two localities Marawa (Bada Buna) and Bore (Askola) around Jimma Town (Fig. 1). These clay soil samples were investigate at Jimma University laboratory.

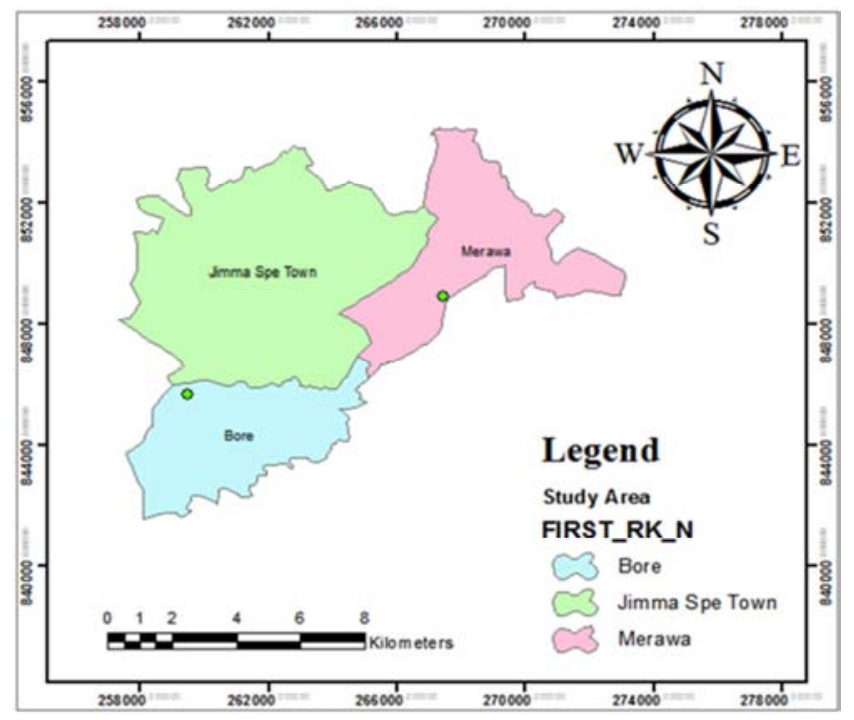

Fig. 1. Point locations of sampling sites.

\subsection{Preparation of the Raw Materials}

The procedures employed in this study for the production of clay bricks include preparation of the raw materials, mixing, shaping, drying and firing of bricks. The procedures of clay soil sample collection and methods of preparation of the bricks for firing is shown in Fig. 2. The index properties of the soil samples from the two localities are given in Table 1.

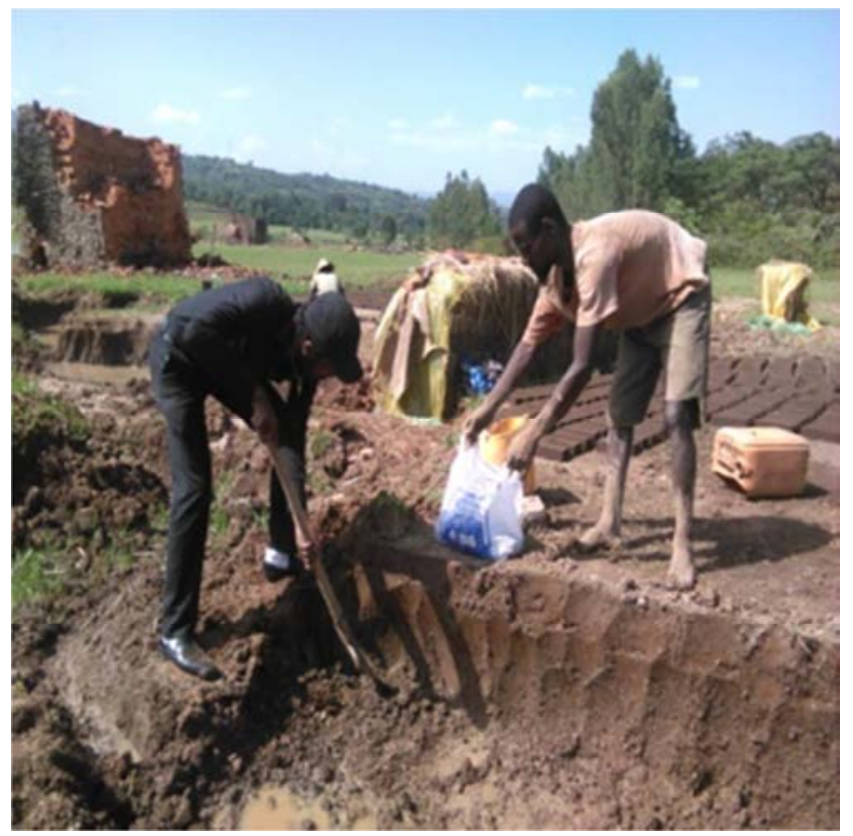

Fig. 2. Photo taken during the collection of soil sample (February 2016).

The red clay soil from Bada Buna and the greyish clay soil from Bada Buna were transported to the production site. The production site for this study is in Jimma Town. The samples were dried in an open air. The oversized soil particles are manually crushed and sieved again and again before molding to produce bricks for firing.

\subsubsection{Forming}

For the production of clay bricks from the two soil samples, each sample was mixed with water and the amount of water used for mixing is based on the plastic and liquid limit of the soil samples. Mixing of the soil sample with water was done manually. Shaping of the mixed soils at their plastic state was done using a wood mould of size $25 \mathrm{~cm} \times 12$ $\mathrm{cm} \times 6 \mathrm{~cm}$ for the clay soil from Bada Buna, while a mould size $25 \mathrm{~cm} \times 12 \mathrm{~cm} \times 6 \mathrm{~cm}$ was used for the sample from Askola site. Since the furnace available in the laboratory for firing the bricks is very small, such small size mould is selected. Moreover, wood ash is used to lubricate the formwork so that it prevents the plastic raw material mix from sticking on the formwork. All the shaping activities were done manually. During shaping the plastic clay was compacted manually to reduce the void in the mix.

\subsubsection{Drying}

The green bricks were kept in a room for four days, then placed in a shed to be dried with air for six days. The time of 
drying is dependent on the moisture content of the green bricks and the humidity of the production area.

\subsubsection{Firing}

Firing of the dried brick at temperature 700, 970 and $1200^{\circ} \mathrm{C}$ was done using furnace (Fig. 3) at Mechanical Engineering Department Testing Laboratory, Jimma Institute of Technology. The clay bricks were fired separately at different firing duration keeping the temperature constant.

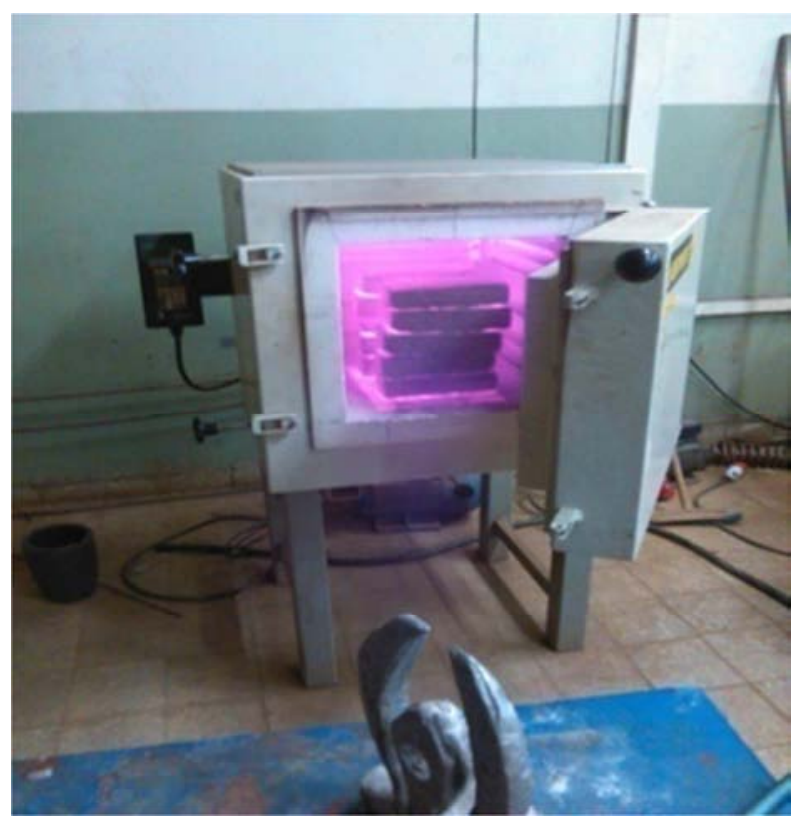

Fig. 3. Firing brick samples in a furnace. the physical and mechanical properties of these bricks.

\subsubsection{Laboratory Tests of the Fired Clay Bricks}

CS, WA and SC of the fired clay bricks separately produced from the two sites were tested in the Construction Materials Testing Laboratory at Jimma Institute of Technology, according to the Ethiopian Standard Specification for Solid Clay Bricks. The test results are analyzed based on the Ethiopian standard specification of solid clay bricks $[3,8]$.

Table 1. Physical properties of sampled soils.

\begin{tabular}{llllll}
\hline Soil sample & LL & PL & PI & $\begin{array}{l}\text { Specific } \\
\text { gravity } \\
\left(\mathbf{g} / \mathbf{c m}^{\mathbf{3}}\right)\end{array}$ & $\begin{array}{l}\text { Water used for } \\
\text { mixing (\% by weight) }\end{array}$ \\
\hline Beda Buna & 38 & 28 & 10 & 2.5 & 30 \\
Askola & 62 & 40 & 22 & 2.48 & 47 \\
\hline
\end{tabular}

\subsection{Data Analysis and Presentation}

The numerical values of the mechanical properties of the fired clay bricks were the mean of five bricks produced using each of the soil samples collected from Bada Buna and Askola. The analyzed data are presented using table and figure.

\section{Results and Discussions}

Properties of the fired Clay Bricks

The experimental tests include determination of CS, WA and the SC of the fired clay bricks. The plot of mean CS of the fired clay bricks versus firing temperature is presented in Fig 4.

Moreover, the bricks produced from the two sites are fired for $2,4,6$ and $8 \mathrm{~h}$ separately at a constant temperature of $970^{\circ} \mathrm{C}$ to test the effects of duration of firing temperature on

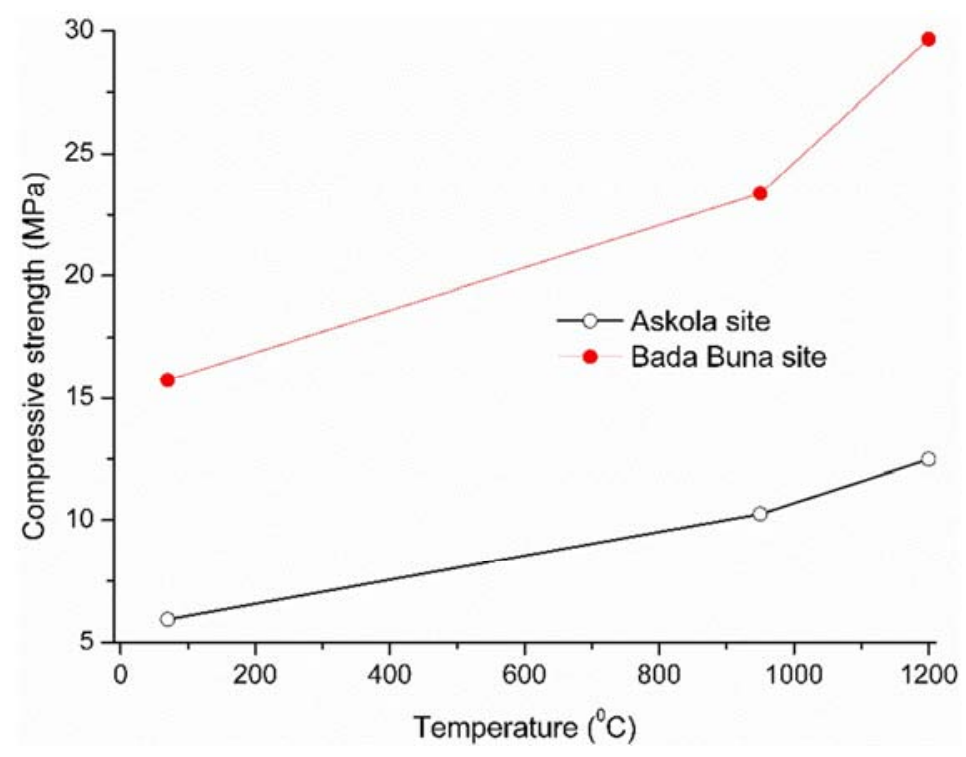

Fig. 4. Plot of mean CS versus firing temperature.

The average CS of five bricks produced using soil samples from Bada Buna and Askola increases as the firing temperature rises from 700 to $1200^{\circ} \mathrm{C}$. Particularly the rapid increment in $\mathrm{CS}$ occurs above $700^{\circ} \mathrm{C}$ (Fig. 4), which could be due to vitrification phenomenon.

The average CS of five bricks separately produced from 
the two soil samples and their classification is given in Table 2. The results show the increase of the CS with the increase in the firing temperature from 700 to $970^{\circ} \mathrm{C}$. The plot of the mean CS of the bricks versus duration of firing is presented in Fig. 5.

Table 2. Average CS of bricks and their classification.

\begin{tabular}{|c|c|c|c|c|}
\hline \multirow{2}{*}{ Raw materials } & \multirow{2}{*}{ Firing Temperature $\left({ }^{\circ} \mathrm{C}\right)$} & \multirow{2}{*}{ Mean CS (MPa) } & \multicolumn{2}{|l|}{ Classification } \\
\hline & & & (ES 86:2001) & ASTM \\
\hline \multirow{3}{*}{ Bada Buna } & 700 & 15.74 & $\mathrm{~B}$ & NW \\
\hline & 970 & 23.37 & A & SW \\
\hline & 1200 & 29.67 & A & SW \\
\hline \multirow{3}{*}{ Askola } & 700 & 5.93 & - & - \\
\hline & 970 & 10.25 & $\mathrm{C}$ & - \\
\hline & 1200 & 12.48 & $\mathrm{C}$ & SW \\
\hline
\end{tabular}

It was observed that the clay bricks produced from soil samples containing a larger proportion of white clay soils from Askola started melting at a lower temperature than the one which has a larger amount of red clay soils from Bada Buna. This may imply that the melting point of the white soil sample is lower than the red soil sample. Therefore, the degree of firing is also dependent on the soil type, which depends on the composition of soil parent material. According to the CS results, the optimum firing temperature of bricks produced from Bada Buna site soil samples is from 970 to $1200^{\circ} \mathrm{C}$, but the $\mathrm{CS}$ of clay brick produced using clay soil from Askola site has lower CS as compared to bricks produced using clay soil from Bada Buna site. The difference in CS could be the difference in the nature of the soil.

At 700 and $970^{\circ} \mathrm{C}$, bricks produced using soil from Askola site, have minimum CS compared with the CS of bricks produced using clay soil from Bada Buna. The difference in $\mathrm{CS}$ could be due to variation in mineral content of the soil.

At $120^{\circ} \mathrm{C}$, maximum $\mathrm{CS}$ is demonstrated by bricks produced using soil from the Bada Buna compared to that of Askola clay soil. The possible reason for this is due to variation of physical properties of clay soil.

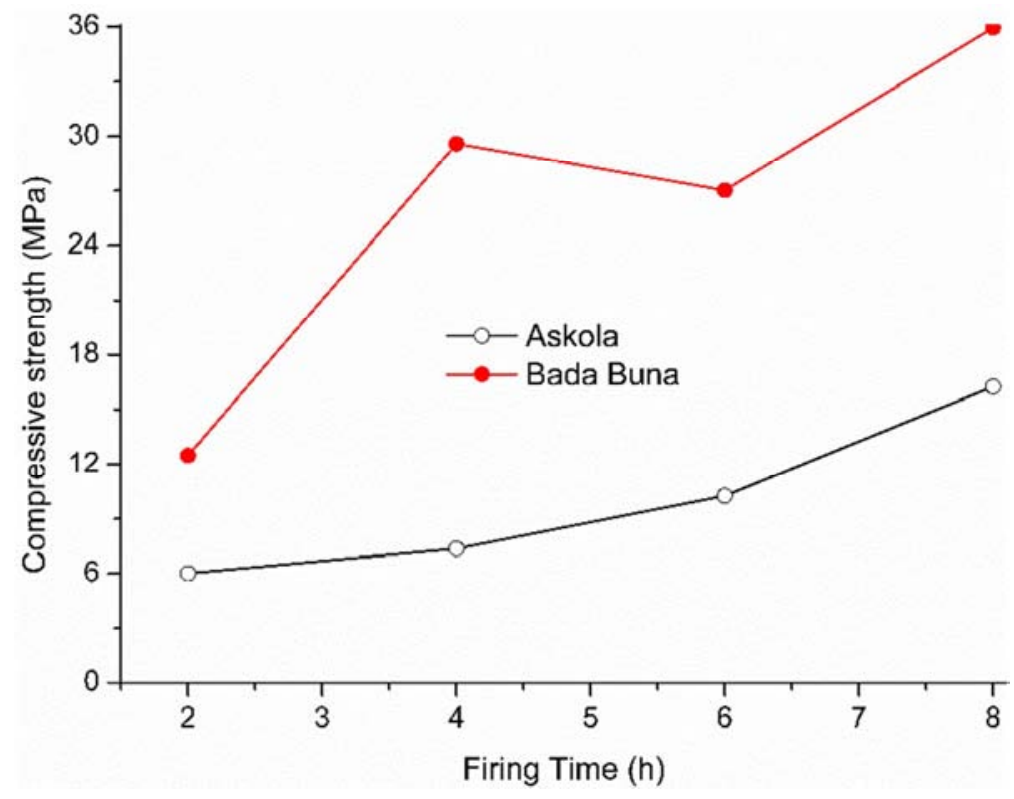

Fig. 5. CS of bricks produced at $970^{\circ} \mathrm{C}$ with varying firing duration.

The bricks produced using soil from Bada Buna fired at $970^{\circ} \mathrm{C}$ demonstrate higher in $\mathrm{CS}$ as compared to bricks produced using clay soils from Askola site as the duration of firing increases (Fig. 3).

Table 3. Average WA and SC of bricks and their classification.

\begin{tabular}{|c|c|c|c|c|c|c|c|}
\hline \multirow{2}{*}{ Raw materials } & \multirow{2}{*}{ firing temperature $\left({ }^{\circ} \mathrm{C}\right)$} & \multicolumn{3}{|c|}{ Mean WA and brick classification } & \multicolumn{3}{|c|}{ Mean SC and brick classification } \\
\hline & & WA (\%) & (ES 86: 2001) & ASTM & SC & (ES 86: 2001) & ASTM \\
\hline \multirow{3}{*}{ Beda Buna } & $700^{\circ} \mathrm{C}$ & 6.38 & A & SW & 0.76 & $\mathrm{~A}, \mathrm{~B}$ & SW \\
\hline & $970^{\circ} \mathrm{C}$ & 6.52 & A & SW & 0.68 & $\mathrm{~A}, \mathrm{~B}$ & SW \\
\hline & $1200^{\circ} \mathrm{C}$ & 8.80 & A & SW & 0.88 & A, B & MW \\
\hline \multirow{3}{*}{ Askola } & $700^{\circ} \mathrm{C}$ & 17.35 & A & MW & 0.86 & A, B & MW \\
\hline & $970^{\circ} \mathrm{C}$ & 10.80 & A & SW & 0.66 & $\mathrm{~A}, \mathrm{~B}$ & SW \\
\hline & $1200^{\circ} \mathrm{C}$ & 19.64 & A & MW & 0.84 & $\mathrm{~A}, \mathrm{~B}$ & MW \\
\hline
\end{tabular}


Table 4. WA and SC of bricks produced from Bada Buna and Askola fired at $970^{\circ} \mathrm{C}$ under different firing duration.

\begin{tabular}{|c|c|c|c|c|c|c|c|c|}
\hline \multirow{2}{*}{ Raw materials } & \multirow{2}{*}{ Firing Temperature $\left({ }^{\circ} \mathrm{C}\right)$} & \multirow{2}{*}{ Firing time (h) } & \multicolumn{3}{|c|}{ Mean WA and brick classification } & \multicolumn{3}{|c|}{ Mean SC and brick classification } \\
\hline & & & WA (\%) & (ES 6:2001) & ASTM & SC & (ES 86:2001) & ASTM \\
\hline \multirow{4}{*}{ Bada Buna } & \multirow{4}{*}{$970^{\circ} \mathrm{C}$} & 2 & 10.01 & A & SW & 0.84 & $\mathrm{~A}, \mathrm{~B}$ & MW \\
\hline & & 4 & 7.92 & A & SW & 0.69 & A, B & SW \\
\hline & & 6 & 6.57 & A & SW & 0.69 & A, B & SW \\
\hline & & 8 & 5.58 & A & SW & 0.69 & $\mathrm{~A}, \mathrm{~B}$ & SW \\
\hline \multirow{4}{*}{ Askola } & \multirow{4}{*}{$970^{\circ} \mathrm{C}$} & 2 & 37.51 & C, D & NW & 0.96 & A, B & NW \\
\hline & & 4 & 26.31 & C, D & NW & 0.82 & A, B & MW \\
\hline & & 6 & 12.23 & A & SW & 0.75 & A, B & SW \\
\hline & & 8 & 11.89 & A & SW & 0.72 & A, B & SW \\
\hline
\end{tabular}

The physical property requirements of fired clay bricks are different in becasuse of the difference in standard specifications of each nation. This is due to the fact that based on the existing weathering conditions. For instance, lower values of WA are required in British Standard Specification for classifying clay bricks when compared with other standard specifications [8,3].

The mean WA and SC of bricks and classification of the bricks based on WA and SC is given Table 3. For instant based on mean WA, the bricks are classified as a class A according to [8], whereas the same bricks are classified as MW based on ASTM Standard Specification. This shows that classification of fired bricks differs based on different standard specifications. According to the requirement of [8, 14], the clay bricks produced from the same raw materials, from clay soils from Bada Buna site fired at $700^{\circ} \mathrm{C}$, as shown in Tables 2 and 3, are classified as class B, A and A, B based on their mean CS, mean WA and mean WA, respectively.

The mean WA and SC are reduced for all the bricks produced from both soils as the firing temperature increases (Table 3). Moreover, the results of mean WA and SC of bricks produced from Bada Buna site which are fired at constant temperature of $970^{\circ} \mathrm{C}$ for different duration (Table 4) as the duration of firing increases. The WA and SC of bricks, the important physical properties of bricks, are improved as the firing temperature and duration of firing increase within the optimum firing temperature range.

During the experimental production processes of the fired clay bricks using the clay soils from the two sites, the sizes of the green bricks, the air dried bricks and the fired bricks were measured. Accordingly, it was observed that the sizes of all bricks decreased as the bricks lose their moisture due to drying and firing, and the mean sizes of bricks measured at different stages of production processes are given in Table 5.

Table 5. Mean sizes of green bricks, air dried bricks and fired bricks.

\begin{tabular}{|c|c|c|c|c|}
\hline Sample site & Size of green bricks $(\mathrm{cm})$ & Mean size of air dried bricks (cm) & Firing temperature $\left({ }^{\circ} \mathrm{C}\right)$ & Mean size of fired bricks $(\mathrm{cm})$ \\
\hline \multirow{3}{*}{ Bada Buna } & \multirow{3}{*}{$25 \times 12 \times 6$} & \multirow{3}{*}{$23.2 \times 11.2 \times 5.9$} & 700 & $22.60 \times 10.58 \times 5.60$ \\
\hline & & & 970 & $22.80 \times 10.54 \times 5.34$ \\
\hline & & & 1200 & $22.62 \times 10.26 \times 5.36$ \\
\hline \multirow{3}{*}{ Askola } & \multirow{3}{*}{$25 \times 12 \times 6$} & \multirow{3}{*}{$23.1 \times 11.4 \times 5.7$} & 700 & $22.60 \times 10.54 \times 5.40$ \\
\hline & & & 970 & $22.66 \times 10.50 \times 5.48$ \\
\hline & & & 1200 & $22.62 \times 10.60 \times 5.44$ \\
\hline
\end{tabular}

\section{Conclusions and Recommendations}

Based on the results of this study, the following conclusions and recommendations are drawn:

1. The optimum firing temperature for the production of clay bricks using clay soils from Bada Buna site is from 970 to $1200^{\circ} \mathrm{C}$ while for the bricks from Askola it is from 900 to $970^{\circ} \mathrm{C}$. As the optimum firing temperature increase the CS of the fired clay bricks increases and; the WA and WA of the clay-bricks decrease. This verify that firing temperature significantly affect the physical requirements of fired bricks.

2. Varying the duration of firing from 2 to $8 \mathrm{~h}$ under constant firing temperature, causes slight increase in the mean CS and minor decrease in the WA and SC.

3. Physical properties of fired bricks produced from clay soils of the study area at firing temperature of 970 and $1200^{\circ} \mathrm{C}$ satisfy the Ethiopian Standard Specification for
Solid Clay Bricks (ES 86: 2001). However, clay bricks produced at different firing temperatures have different CS, WA and SC.

4. People involved in the production of fired clay bricks in the study area need to be trained on how to control or financially assisted to buy kiln temperature controlling device.

5. Encouraging both domestic and foreign investments in the brick production sector plays a decisive role to modernize the clay brick production system. Moreover, it creates competition in terms of quality and cost in this sector.

\section{Acknowledgments}

I am grateful to Jimma University and Ethiopian Road Authority for funding the study and allowing me to use the laboratory facilities. I would like also to thank Traditional Brick Making Micro Enterprises in Jimma Town. 


\section{References}

[1] Abebe Dinku, A. Z. (2004). Assessments of locally produced brick's quality for construction purposes, EACE Bulletin Volume. 6. No.1.

[2] Abebe Dinku (2002). Construction materials laboratory manual. AAU Printing Press.

[3] ASTM C67-90. (1996). Standard test method for the properties of fired clay bricks "Annual Book of American Society for Testing and Materials".

[4] Altayework Tadesse (2013). Effects of firing temperature on physical properties of burnt clay bricks produced around Addis Ababa. Unpublished M.Sc Thesis. Addis Ababa University.

[5] Brick making enterprises in Hai Duong, H. Y. (2004). Vertical shaft continuous kiln (VSCK) in brick making industry, Vietnam's thermology science and technique institute.

[6] Brick Products Production Share Company. (2013). Verbal communication with Finance and Administration Head of Brick Products. Addis Ababa.

[7] British Standard Institution. (1985). British Standard Specification for clay bricks (BS 3921).

[8] Ethiopian Standards Agency (ESA). (2011). Solid clay bricks, ES 86:2001, Ethiopian Standard, Second edition 2001-06-27.

[9] Hung Yen, D. N. (2004.). Vertical shaft continuous kiln (VSCK) in brick making industry, Brick making enterprises. Vietnam's Thermology Science and Technique Institute.

[10] Karaman. (2006). Firing temperature and time influence on clay bricks properties. Journal of Scientific \& Industrial Research, 154-155.

[11] Mbumbia I, D. W. (2000). Performance characteristics of lateritic soil bricks fired at low temperatures. Case study of Cameroon, Const Build Mat, 121-131.

[12] The ASTM Committee on Standards. (1999). Annual book of ASTM standards, Volume 04.05, "Standard specification for building bricks (Solid masonry units made from clay or shale)". ASTM C 62-97a.

[13] The Federal Democratic Republic of Ethiopia. (2004). Central Statistical Authority. Welfare monitoring survey, analytical report.

[14] Syed Ashraful Alam, (2006). Use of biomass fuels in the brick-making industries of Sudan: Implications for deforestation and greenhouse gas emission, Thesis submitted for M. Sc. Degree in Forest Ecology, University of Helsinki, Finland.

[15] Solid clay bricks, ES 86:2001 (2001), Ethiopian Standard, Second edition 2001-06-27.

[16] Ethiopian Standards Agency (ESA), 2011. 